\title{
Assessment of environmental-economic effectiveness of multifunctional fuel additives
}

\author{
L. L. Abrzhina \& E. R. Magaril \\ Department of Environmental Economics, \\ Ural Federal University, Russia
}

\begin{abstract}
The quickest solution to the urgent problem of improving the environmental safety and effectiveness of automobile transport operation with minimal expenditure is possible through the application of fuel additives positively affecting the motor fuel properties. The use of multi-functional additives that have a multi-purpose positive impact on fuel properties is the most attractive way. The absence of a method of comparative assessment of different additives makes the use of additives that improve some properties of fuels concurrently impairing other properties possible, or increase toxicity of exhaust gases, or considerably increase the cost of fuel.

The aim of this paper is to develop scientific and methodological basis and specific methodology for assessing environmental-economic efficiency of additives to motor fuels. The authors identified the system of factors forming a structure of environmental-economic effect resulting from the application of multifunctional fuel additives, and also developed a method of assessment of environmental-economic efficiency of application of fuel additives, including the steps of integrated assessment of environmental-economic effectiveness and optimization in operational conditions.
\end{abstract}

Keywords: assessment of environmental-economic effectiveness, additives to motor fuels, economic and environmental consequences.

\section{Introduction}

The rapid growth of the vehicle fleet along with the steady or even degraded fuel quality over the past 20 years in Russia has led to the sharp deterioration of the urban environment, which entails serious negative social and economic 
consequences. A partial solution of the problem is possible through the implementation of environmental protection measures improving the motor vehicles operation, giving the same (or greater) effect at a lower cost as modernization in the motor or oil refining industry. Considering the specificity and difficulties of the Russian economy, this solution of the problem of increasing environmental safety, efficiency and reliability of vehicle operation would be optimal for Russia and other countries with transitional economy. Reducing the costs of achieving the desired result of environmental measures is also relevant for developed countries.

In the current state of Russian economy the usage of fuel additives is the most reasonable atmosphere protecting measure, which allows quickly and costeffectively improvement of the environmental and operational performance of the vehicles [1-7]. A methodological framework for the assessment of additives application efficiency should be developed to make valid decisions on their implementation.

\section{Methodological framework for the assessment of environmental-economic effectiveness of multifunctional fuel additives}

The authors have formulated the principals for methodological assessment of the environmental-economic effectiveness of fuel additives:

1. Cost and benefit ratio principle.

2. An integrated approach: the effect of the additives implementation should include both positive and negative results.

3. Benefits and costs should include economic and environmental components, considering the principle of parity (equivalence).

4. Any potential effect of additives, both positive and negative is possible.

The proposed scheme of assessment of environmental-economic fuel additives effectiveness is shown in figure 1.

Analytical studies of methodological approaches to the assessment of economic and environmental efficiencies of environmental protection measures allowed the authors to formulate a methodological framework for the assessment of integrated environmental-economic fuel additives efficiency:

1. Only additives which meet the specified requirements are selected.

2. The integral environmental-economic efficiency $\left(E_{e e}\right)$ may be defined as the ratio of the environmental-economic effect of the event $(R)$ to the additional costs for its implementation $(C)$ :

$$
E_{e e}=R / C \text {. }
$$

3. The value of the integral environmental-economic effect can be defined as the difference between the benefits of the implementation of environmental protection measure $(B)$ and additional costs $(C)$ that accompany its achievement:

$$
P=B-C \text {, monetary units. }
$$




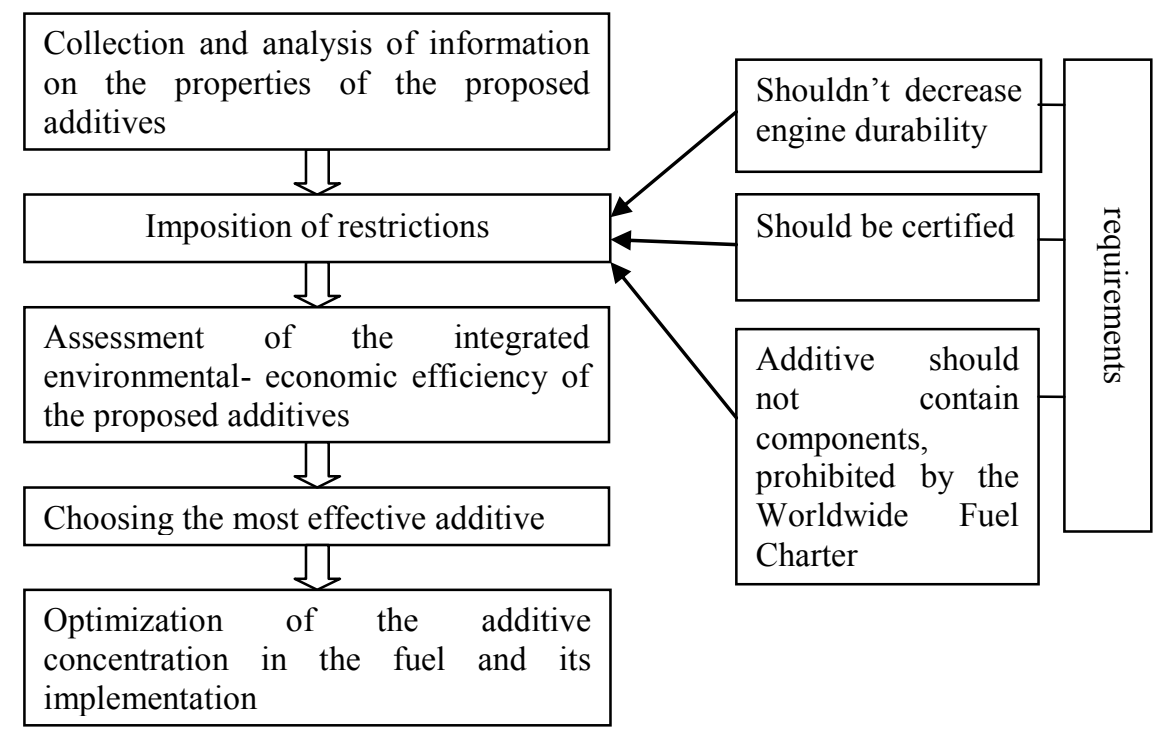

Figure 1: Assessment scheme of fuel additives environmental-economic efficiency.

4. The benefit of the environmental protection measures implementation is equal to the set of positive values both economic $\left(\mathrm{B}_{\mathrm{ec}}\right)$ and environmental $\left(\mathrm{B}_{\text {en }}\right)$ :

$$
B=B_{e c}+B_{e n} \text {, monetary units. }
$$

5. Additional costs are the set of material-financial resources expense (economic costs $\mathrm{C}_{\mathrm{ec}}$ ) and the valuation of the entire complex of the negative environmental effects in case of environmental measures implementation $\left(\mathrm{C}_{\mathrm{en}}\right)$ :

$$
C=C_{e c}+C_{e n} \text {, monetary units. }
$$

6. The time factor can be excluded from the value of the integral environmental-economic effect calculations, since the financial costs invested in the implementation of the environmental measures, and the main result from the additives usage belong to the same time period.

7. The additives introduction does not require capital investments, so, the cost of implementation of environmental protection measure will be current.

8. The total sum of the integral environmental-economic effect $(R)$, formed as a result of environmental protection measure implementation, can be calculated as:

$$
R=\left(B_{e c}+B_{e n}\right)-\left(C_{e c}+C_{e n}\right) \text {, monetary units. }
$$

9. Therefore, the environmental-economic efficiency $E_{e e}$ of environmental protection measure can be calculated as the following: 


$$
E_{e e}=\frac{\left(B_{e c}+B_{e n}\right)-\left(C_{e c}+C_{e n}\right)}{C_{e c}+C_{e n}} .
$$

\section{Environmental-economic assessment methods of fuel additives implementation efficiency}

The analysis of the additives influence on the quality of fuels, environmental and performance characteristics of vehicles, allowed the authors to define the components of the environmental-economic effect of their implementation (figure 2).

The proposed method of environmental-economic fuel additives implementation efficiency assessment includes 2 stages:

Stage 1 - Assessment of the integral environmental-economic efficiency of additives application;

Stage 2 - Optimization of the content of the additive in the fuel.

\subsection{Integral environmental-economic assessment of fuel additives implementation}

The assessment phase of integral environmental-economic efficiency allows a decision to be taken on the possibility of specific additives usage or to choose between the alternatives.

The proposed method of evaluation of integral environmental-economic efficiency of fuel additives implementation is based on:

- the proposed methodological principles;

- the basis of a common methodological approach to the evaluation of integral environmental-economic efficiency of environmental protection measures;

- the system of factors, forming independent result and costs components from the fuel additives usage.

According to the authors, not only should the environmental damage caused by polluting toxic substances, but also other negative consequences for the atmosphere, namely, from carbon dioxide release and consumption of oxygen during combustion, be considered when accounting for the negative environmental impacts of the vehicles operation.

The environmental damage caused by carbon dioxide is understood to be a pecuniary valuation of negative changes in the environment as a result of carbon dioxide discharge into the atmosphere within the industrial and transport emissions and the effects of such changes. The environmental damage caused by anthropogenic oxygen consumption is understood to be a pecuniary valuation of negative changes in the environment as a result of oxygen consumption in technological processes and the impact of such changes [8].

Thus, an integral environmental-economic efficiency of fuel additives can be determined from the following formula: 


\begin{tabular}{l} 
Factors, forming the environmental-economic effect of fuel additives \\
\hline application
\end{tabular}

Figure 2: Factors forming environmental-economic effect of fuel additives application. 


$$
\begin{gathered}
E_{e e} *=\left(\left(B_{e c_{1}}+B_{e c_{2}}+B_{e c_{3}}+B_{e c_{4}}\left(B_{e c_{6}}\right) * *+B_{e c_{5}}+B_{e c_{7}}+B_{e c_{8}}+B_{e n_{1}}+\right.\right. \\
\left.\left.+B_{e n_{2}}+B_{e n_{3}}\right)-\left(C_{e c_{1}}+C_{e c_{2}}+C_{e c_{3}}+C_{e c_{4}}+C_{e c_{5}}+C_{e n_{1}}\right)\right) \div\left(C_{e c_{1}}+C_{e c_{2}}+\right. \\
\left.+C_{e c_{3}}+C_{e c_{4}}+C_{e c_{5}}+C_{e n_{1}}\right)
\end{gathered}
$$

where $B_{e c_{1}}$ is a benefit, formed by the reduction in repair costs; $B_{e c_{2}}$ is a benefit from fuel cost reduction due to a decrease in evaporation; $B_{e c_{3}}$ is a benefit from the reduction in fuel consumption due to a decrease in specific fuel consumption; $B_{e c_{4}}$ is a benefit from a cheaper low-octane fuel usage; $B_{e c_{5}}$ is a benefit from reduction in spark plug usage; $B_{e c_{6}}$ is a benefit from the possibility to use light diesel fuel at lower temperatures; $B_{e c 7}$ is a benefit from engine wear reduction (in case of the increase in engine lifetime by the manufacturer); $B_{e c_{8}}$ is a benefit from emission fees reduction; $C_{e c_{1}}$ is additional repair costs; $C_{e c 2}$ is additional fuel costs; $C_{e c 3}$ is additional additives costs; $C_{e c 4}$ is additional spark plug costs; $C_{e c 5}$ is additional costs from emission fees increase; $B_{e n 1}$ is an environmental damage reduction due to a decrease in toxic substances emission; $B_{\text {en } 2}$ is an environmental damage reduction due to a decrease in oxygen consumption; $B_{e n 3}$ is environmental damage reduction due to a decrease in $\mathrm{CO}_{2}$ emission; $C_{e n_{1}}$ is a rise in environmental damage due to toxic substances emission increase.

* In accordance with the 4th principle of the environmental-economic efficiency assessment of the fuel additives implementation, during the calculation of the specific additive efficiency only applicable variables of the environmental-economic effect should be considered.

** Variable is chosen depending on the fuel type to which the evaluated additive is applied.

\subsection{Optimization of additive usage under the vehicle operating conditions}

The method of determination of the optimum concentration of additive in the fuel, developed by the authors, helps to estimate the most effective additive concentration after making a decision on its application.

It is proposed to optimize the concentration of the additive in the fuel in accordance to dominant result of its application (as a priority component of integral environmental-economic effect).

The dominant result is determined as follows:

$$
\gamma_{i}=\frac{B_{i}}{R} \rightarrow \max ,
$$

where $B_{i}$ is a component of integral environmental-economic effect, monetary units; $R$ is an integral environmental-economic effect, monetary units. 
From the above analysis of the known additives influence on the properties of motor fuels determining operational and environmental characteristics of vehicles, and from the physicochemical properties of the additives, it follows that 2 types of mathematical relations are possible regarding additive efficiency and its concentration (figure 3 ).

It is necessary to investigate the effect of additives experimentally on the dominant result and determine the type of dependence, using mathematical and statistical methods. For the first type of correlation dependence the optimal concentration is obtained by equalization to zero of the first derivative:

$$
x=-b / 2 a \text {; }
$$

the second - as a lower bound when efficiency tends to saturation:

$$
x_{\min } \text {, where } y \rightarrow a / b \text {. }
$$

The developed methodical approach to determination of the most effective concentration of the additive in the fuel by establishing correlation dependence with the dominant result of its application allows increasing the decision objectivity on optimization of the additive content in the fuel.

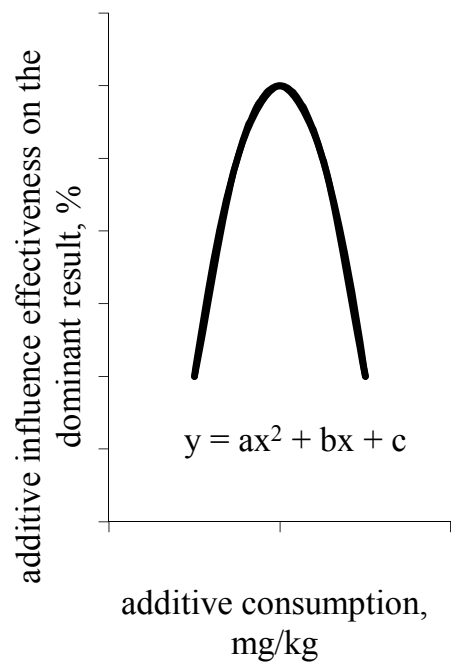

(a)

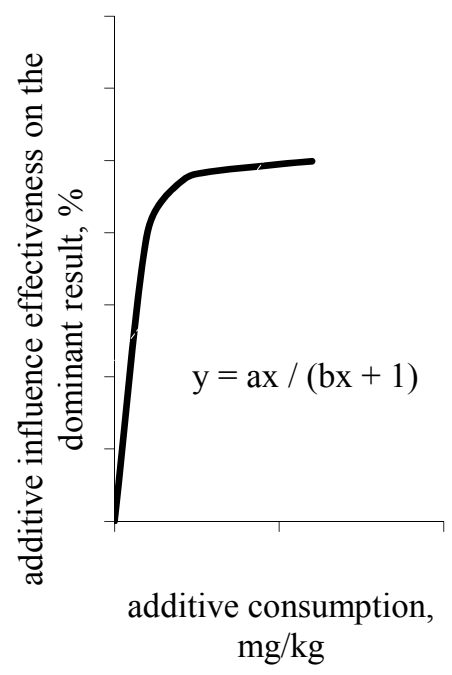

(b)

Figure 3: Types (a), (b) of mathematical relation: $\mathrm{x}$ is an additive concentration, $\mathrm{mg} / \mathrm{kg}$; $\mathrm{y}$ is additive influence effectiveness on the dominant result, $\% ; y=\frac{y_{0}-y_{1}}{y_{0}} \% ; y_{0}$ and $y_{1}$ - factors forming the environmental-economic effect, before and after the additive implementation, monetary units. 


\section{Conclusion}

The components of environmental-economic effect of multifunctional fuel additives are determined. The environmental-economic efficiency assessment method of the fuel additives usage, was formed, based on the authors' methodological approach and identified factors that determine the environmental-economic efficiency. That allows oil refineries management to make reasonable decisions about suitability of the specific additives implementation, which would increase the efficiency and environmental safety of vehicles during operation.

\section{References}

[1] Magaril, E., Improving car environmental and operational characteristics using a multifunctional fuel additive. WIT Transactions on Ecology and the Environment, 147, WIT Press: UK, pp. 373-384, 2011.

[2] Magaril, E., The influence of carbonization elimination on the environmental safety and efficiency of vehicle operation. International Journal of Sustainable Development and Planning, 8(4), pp. 1-15, 2013.

[3] Magaril, E., The solution to strategic problems in the oil refining industry as a factor for the sustainable development of automobile transport. WIT Transactions on Ecology and The Environment, 190, VOLUME 2, WIT Press: UK, pp. 821-832, 2014.

[4] Magaril, E.R., Influence of the quality of engine fuels on the operation and environmental characteristics of vehicles: monograph, (in Russian), KDU: Moscow, 2008.

[5] Magaril, E.R. \& Magaril R.Z., Motor fuels (in Russian), second edition, KDU: Moscow, 2010.

[6] Magaril, E. \& Magaril, R., Motor fuels: the problem of energy efficiency and environmental safety: monograph, (in Russian), LAP LAMBERT Academic Publishing GmbH\& Co: Saarbrücken, Germany, 2012.

[7] Abrzhina, L.L., Justification of the most economic and realizable way to quickly improve the environmental and operational characteristics of the vehicle fleet, (in Russian), Vestnik UGTU-UPI. Seria «Economica $i$ Upravlenie», 2(85), pp. 68-74, 2007.

[8] Magaril E.R., Abrzhina L.L. \& Belyaeva M.A., Environmental damage from the combustion of fuels: Challenges and methods of economic assessment. WIT Transactions on Ecology and The Environment, 190, VOLUME 2, WIT Press: UK, pp. 1105-1115, 2014. 